\title{
APPLICATION OF DNA BARCODING FOR IDENTIFICATION OF SOME KEY FISH-MARKET SPECIES IN SHARJAH CITY, UAE
}

\author{
Alaa Abdelbaset-Donya ${ }^{1}$; Waleed Hamza ${ }^{2}$; Khaled Mohammed-Geba ${ }^{1}$; \\ Asmaa Galal-Khallaf ${ }^{\mathbf{1}^{*}}$ \\ ${ }^{1}$ Zoology Department, Faculty of Science, Menoufia University, Menoufia, Egypt \\ ${ }^{2}$ Biology Department, United Arab Emirates University, Al-Ain, UAE
}

\section{Article History: \\ Received: 21 October 2020 \\ Revised: 9 November 2020 \\ Published Online: \\ 16 November 2020 \\ Keywords: \\ coi gene \\ DNA barcoding \\ Fish species \\ Fish markets \\ UAE \\ *Correspondence: \\ Asmaa Galal-Khallaf \\ Zoology Department \\ Faculty of Science \\ Menoufia University \\ Menoufia, Egypt \\ E-mail: \\ as_kh_22@yahoo.com}

Accepted: 11 November 2020

\section{ABSTRACT}

The United Arab Emirates (UAE) has been identified as an active international seafood market. To identify some of the key fish species in the UAE markets, 9 species of fresh fishes were randomly collected from Souq Al Jubail in Sharjah City, one of the biggest fish markets in UAE. The samples were subjected to DNA barcoding using partial sequencing of the hypervariable $5^{\prime}$ region of the cytochrome oxidase subunit I (coi) gene. Furthermore, the results were phylogenetically analyzed to provide further accurate species identification. Genetic and phylogenetic analyses resolved the naming discrepancies found in $30 \%$ of the fishes. Genetic diversity within each species exhibited a general trend for high haplotypes' diversities. Most haplotypes were shared with the Sea of Oman and the Arabian Gulf, and few with the Red Sea. The results strongly recommend continuous application of molecular-based species inspection in the UAE seafood markets for assuring authenticity, traceability, and proper conservation of the native species.

\section{INTRODUCTION}

Fish and seafood products are among the most worldwide traded food commodities ${ }^{[1]}$. The term "seafood" is used to refer edible aquatic life forms, including fish, mollusks, crustaceans, and echinoderms. The world supply of fish and seafood is steadily increasing, reaching 178.8 million tons in $2018^{[2]}$. In 2015, the United Arab Emirates (UAE) imported what worth 624 million US Dollar (USD) of fish and fisheries products, while exported about 100 million $\mathrm{USD}^{[3]}$. The UAE is engaged in a substantial level of re-exporting fish and fisheries products (68 million USD in 2015), whose origins are imports from neighboring countries, especially Oman. UAE is also an approved exporting country to the European Union ${ }^{[3]}$. According to the data of the Environment Agency of Abu Dhabi ${ }^{[4]}$, the UAE fishing sector represents $0.12 \%$ (more than 450 million USD) of the country's gross domestic product (GDP). The UAE imports fulfill $72 \%$ of the country's seafood requirements, while the local fishing sector contributes $27 \%$. With the increased seafood imports and inefficient monitoring, fraud and misrepresentation in seafood marketing is becoming increasingly prevalent ${ }^{[5]}$. Processed and packed seafood products can be changed or replaced, either partially or completely ${ }^{[1]}$. Moreover, there are many critical issues with food fraud for specific community groups such as vegetarian people 
and allergic persons, besides the religious prohibitions. Therefore, detecting of processed and/or packed species is necessary for reducing economical fraud and health risks.

DNA-related methodologies are of highest relevance for species identification since the DNA is highly preserved and resistant to food processes; such as smoking, heating, curing, acidification, etc. Many of these techniques base on the use of short DNA sequences, e.g. the DNA barcodes. Since its establishment, DNA barcoding continued to provide a rapid and cheap protocol for accurate species identification ${ }^{[6]}$. The comparison of interspecific, hypervariable sequences of short genomic fragments to a genetic database could achieve several advances in market surveillance and solving many ambiguities related to misidentification of species or economic frauds ${ }^{[6,7]}$. Applying phylogenetic methodologies as a synergistic technique with DNA barcoding is frequently carried out $^{[8]}$. The mitochondrial genomes are known to have several advantages for this purpose. Chiefly, in having high rates of mutation compared to the nuclear genomes, matrilineal mode of inheritance in vertebrates, hence exhibiting no hybridization or allelic variations, have a high copy number; as well as the availability of its references in several related genetic databases, e.g. BOLD and GenBank ${ }^{[8,9]}$. All these criteria can strongly facilitate the rapid and costeffective surveillance of different species present in the seafood markets as a way to combat seafood fraud and induce the national and international key popular interest of guaranteeing food traceability and authenticity. The current pilot study aimed to provide mitochondrial molecular tools to the national authorities in the UAE for aiding rapid and accurate authentication of fresh and frozen seafood species in some UAE markets, which encompasses one of the most diverse international populations in the Arabian Gulf region.

\section{MATERIAL AND METHODS Ethical considerations}

The samples were obtained from fishes after being fished, landed, and sold for human consumption. According to the Committee for Animal Ethics in the Zoology Department, Faculty of Science, Menoufia University, no permits are required to conduct this market-based study.

\section{Sampling}

Forty-five fresh samples, but not alive fish, were collected from Souq Al Jubail, one of the biggest fish markets in UAE, in Sharjah City $\left(25^{\circ} 26^{\prime} 0^{\prime \prime} \mathrm{N}, 55^{\circ} 23^{\prime} 0^{\prime \prime} \mathrm{E}\right.$, Figure 1$)$. This market mainly receives the Emirati fish landings from the Arabian Gulf and Sea of Oman. The targeted species represented the most 9 species widely sold in the market. These species are named locally by fishermen as: hamour, jesh TT, jesh sal, jesh farow, shaari arabi, shaari eshkheli/baskili, marjaan/al-hamra, naiser, and dog fish/baby shark (Figure 2, Table 1). From each species, five specimens were collected. Fin clips from each sample were dissected, preserved in $96 \%$ ethanol and stored at $4^{\circ} \mathrm{C}$. The samples were then shipped to the Molecular Biology and Biotechnology Laboratory of the Zoology Department in the Faculty of Science of Menoufia University in Egypt for subsequent genetic analysis.

\section{DNA extraction}

DNA extraction was carried out from fish fin clips using the method described by Mohammed-Geba et $a l^{[10]}$. Briefly, $200 \mu \mathrm{L}$ of Tris base-NaCL-ethylenediaminetetraacetic acid (EDTA)-sodium dodecyl sulfate (TNES)-urea buffer with $2.4 \mathrm{U} \mathrm{mL}^{-1}$ proteinase $\mathrm{K}$ solution (Thermo Fischer Scientific, Waltham, MA, USA) was added to the individually lysing fin clips, with incubation at $65^{\circ} \mathrm{C}$ for 10 minutes (min). Then, $54 \mu \mathrm{L}$ of $5 \mathrm{M} \mathrm{NaCl}$ was added; the tubes were repeatedly inverted for mixing, and centrifuged at $4000 \times g$ for $10 \mathrm{~min}$. The aqueous supernatant was removed to a new, sterile $1.5 \mathrm{~mL}$ tube, and freeze-cold isopropyl alcohol $(200 \mu \mathrm{L})$ was added with shacking to precipitate the DNA. 


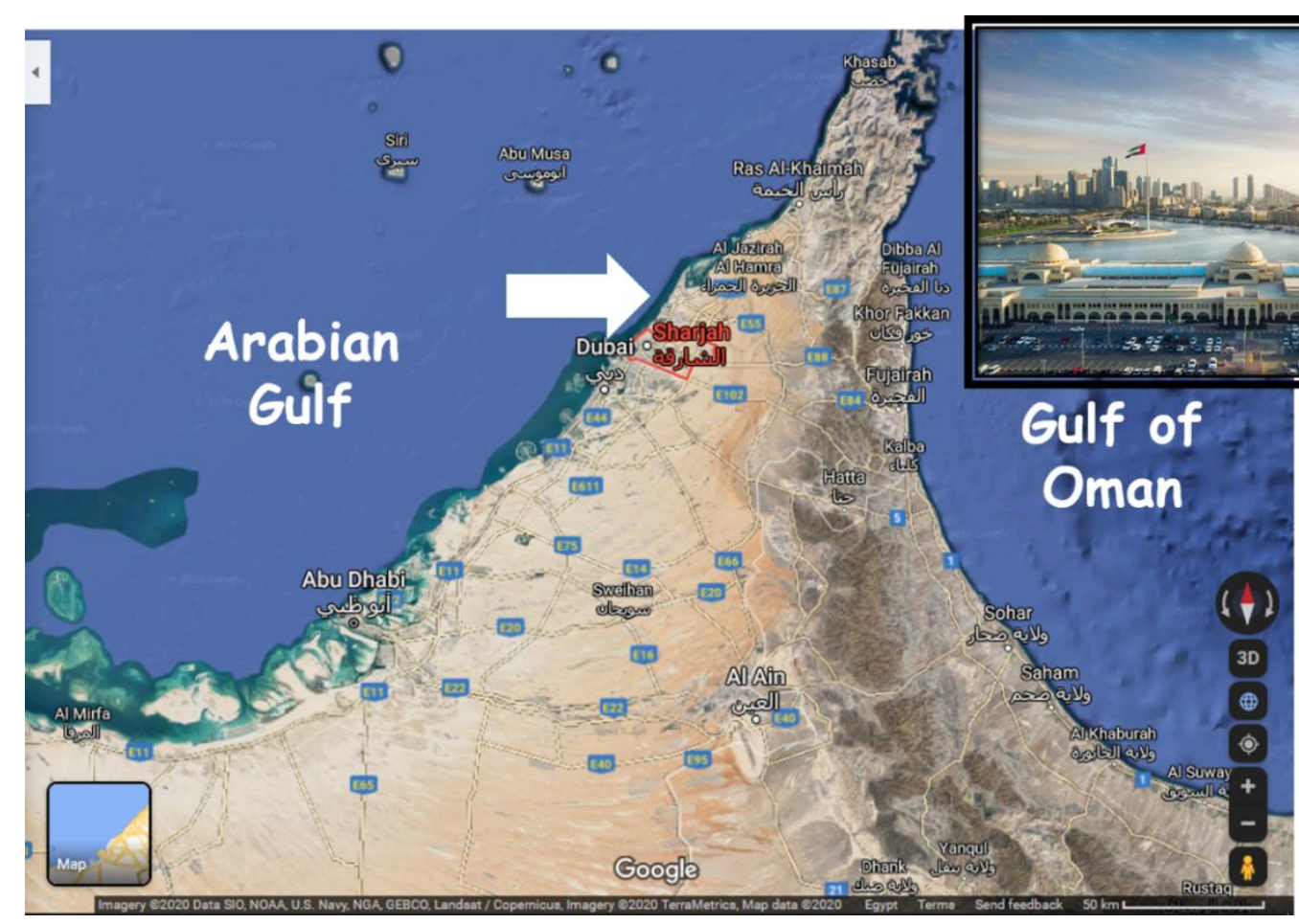

Figure 1: Map for the UAE showing the location and photos of Souq Al Jubail fish market, Sharjah City. The white arrow refers to Sharjah Principality, UAE.

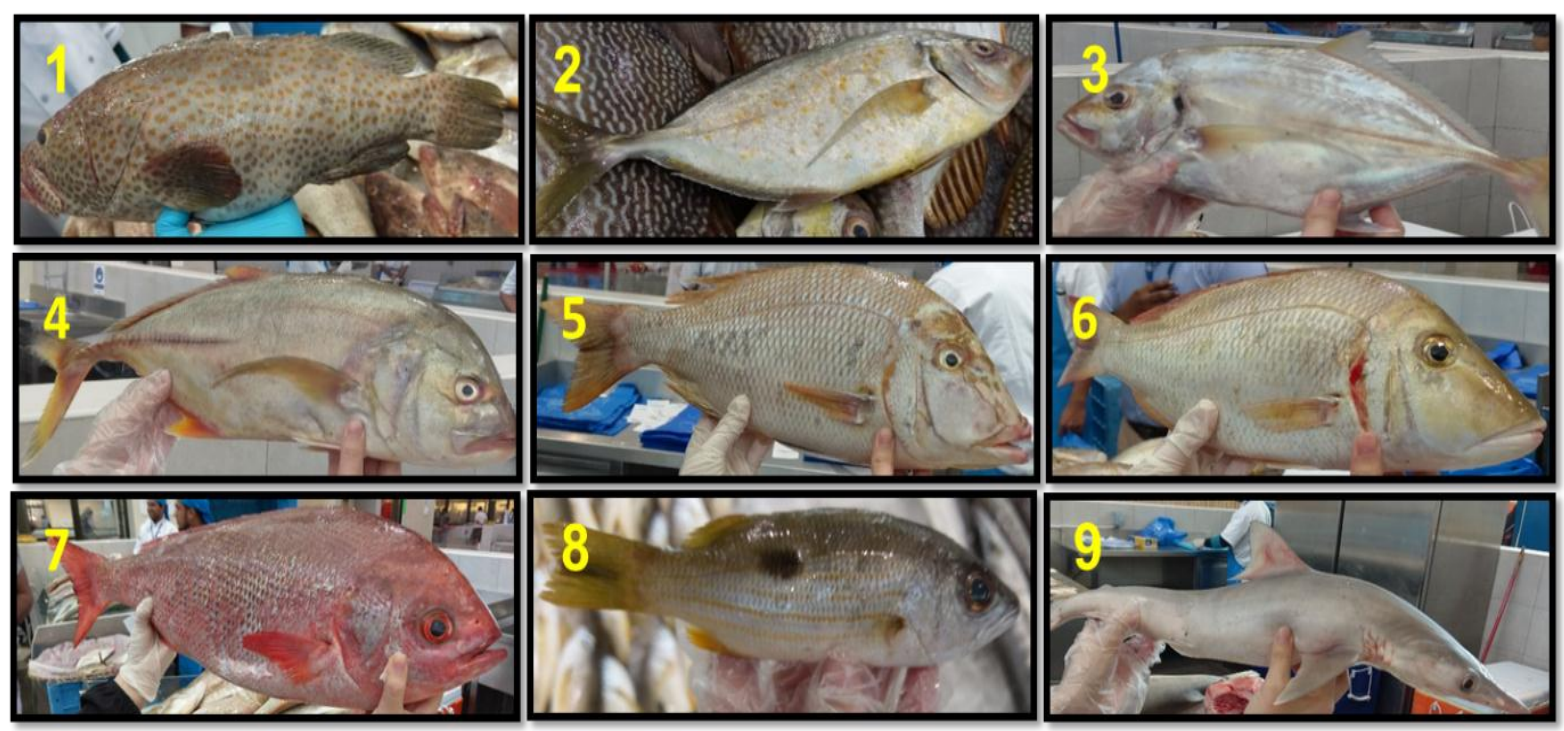

Figure 2: The collected fish species from Souq Al Jubail fish market, Sharjah City: 1: hamour, 2: jesh TT, 3: jesh sal, 4: jesh farow, 5: shaari arabi, 6; shaari eshkheli/baskili, 7: marjaan /al-hamra, 8: naiser, 9: dog fish/baby shark.

After $11000 \times g$ centrifugation for $10 \mathrm{~min}$, the supernatant was replaced by $400 \mu \mathrm{L}$ of $70 \%$ ethanol for washing the DNA pellet. The tubes were re-centrifuged for $5 \mathrm{~min}$ at $11000 \times g$, the ethanol was completely removed. Finally, Tris EDTA buffer, $30 \mu \mathrm{L}(10 \mathrm{mM}$ Tris- $\mathrm{HCl}, \mathrm{pH}=8$ and $2 \mathrm{mM}$ EDTA, $\mathrm{pH}=8$ ), was added for DNA pellet re-suspension. 
Table 1: The analyzed Sharjah market fish samples using DNA barcoding. Commercial name refers to the name of samples provided by the local fishermen.

\begin{tabular}{llccc}
\hline \multicolumn{1}{c}{ Commercial name } & \multicolumn{1}{c}{ Latin name* } & Identity & $\begin{array}{c}\text { Haplotypes } \\
\text { diversity (Hd) }\end{array}$ & $\begin{array}{c}\text { GenBank } \\
\text { accession numbers }\end{array}$ \\
\hline Hamour & Epinephelus coioides & $99.53 \%$ & 0.6 & \\
Naiser & Lutjanus ehrenbergii & $99.65 \%$ & 1.0 & \\
Shaari arabi & Lethrinus nebulosus & $99.32 \%$ & 0.8 & \\
Shaari baskili & Lethrinus lentjan & $98.04 \%$ & 1.0 & \\
Jesh sal & Carangoides malabaricus & $100 \%$ & 0.7 & MT260407- \\
& Carangoides chrysophrys & $100 \%$ & 1.0 & MT260448 \\
Jesh farow & Caranx heberi & $99.69 \%$ & 0.6 & \\
Jesh TT & Carangoides bajad & $99.84 \%$ & 0.6 & \\
Marjaan/al-hamra & Pinjalo pinjalo & $99.84 \%$ & 0.6 & \\
Dog fish/baby shark & Rhizoprionodon acutus & $99.84 \%$ & 0.8 & \\
\hline
\end{tabular}

*Based on DNA barcoding

Polymerase chain reaction (PCR), sequencing of cytochrome oxidase subunit I (coi)

Intra-specific hypervariable $5^{\prime}$ region of coi was amplified by PCR in all fish samples, using the following universal primers ${ }^{[11]}$ : Fish F1: 5'-TCAACCAACCACAAAGACA TTGGCAC-3 and Fish R1: 5-TAGAC TTCTGGGTGGCCAAAGAATCA-3`. The amplification reaction for each sample was set up as $50 \mathrm{ng}$ of template DNA, 1.0 X MyTaq $^{\mathrm{TM}}$ Red Mix (Catalogue number: BIO-25043; Bioline, London, UK), $0.4 \mu \mathrm{M}$ of each primer, and $200 \mathrm{ng} \mathrm{mL}^{-1}$ bovine serum albumin to a total volume of $25 \mu \mathrm{L}$. PCRs were carried out in the thermal cycler TC512 (Techne, Chelmsford, UK). PCR conditions included $5 \mathrm{~min}$ at $95^{\circ} \mathrm{C} ; 40$ cycles of 30 seconds (s) at $95^{\circ} \mathrm{C}, 30 \mathrm{~s}$ at $56^{\circ} \mathrm{C}, 30 \mathrm{~s}$ at $72^{\circ} \mathrm{C}$; and final elongation $72^{\circ} \mathrm{C}$ at $10 \mathrm{~min}$.

After the PCR reactions, mitochondrial fragments of coi gene were separated on $1.0 \%$ agarose gel electrophoresis stained with $10 \mathrm{mg} \mathrm{mL} \mathrm{m}^{-1}$ ethidium bromide. Molecular ladder (1.0 Kb, Catalogue number: SM0314; Thermo Fischer Scientific) was applied to assess the amplicon size. PCR amplicons were visualized on UV transilluminator (Transilluminator TI 1, Biommetra, Germany). Then, the PCR products were sent to Macrogen, Inc. (Seoul, Korea) for Sanger sequencing.

\section{Species identification}

The obtained DNA sequences were edited manually using Chromas 2.6.6 software to trim the sequence ends. The sequences were compared to GenBank database (http://www.ncbi. nlm.nih.gov/) and BOLD (http://www.boldsystems.org/index.php/IDS OpenIdEngine). To ensure a high level of species assignment, cut-off values > 98\% for identity was used for species identification. Moreover, Clustal W algorithm incorporated in Mega $X$ software $^{[12]}$ was applied to align all sequences belonging to each species. The haplotypes and nucleotide diversities were obtained using DnaSP 5 program ${ }^{[13]}$. Moreover, coi sequences were in silico translated into amino acids to check for the absence of nuclear copies of mitochondrial genes, i.e. nuclear mitochondrial sequences (NUMTs), as inferred from the presence of premature stop codons and indels. Finally, the haplotypes were 
submitted to the GenBank database using Bankit tool (https://www.ncbi.nlm.nih.gov/ WebSub/?tool=genbank).

\section{Phylogenetic analyses}

In order to confirm the basic local alignment search tool (BLAST) and/or BOLD-based species identification, maximum likelihood (ML) phylogenetic analysis was carried out. The best substitution model was identified using ModelTest algorithm integrated to Mega X software. The ML tree was constructed using the best substitution model and 1000 bootstraps as test replicates.

\section{RESULTS}

\section{Genetic and phylogenetic analyses}

Manual trimming of the obtained coi sequences for all fish samples resulted in an average sequence length of 600 base pair (bp). In silico translation of these sequences resulted in the complete absence of premature stop codons, i.e. no NUMTs were amplified. As shown in Table "1", samples labeled as "hamour" exhibited 99.5\% sequence identity with the orangespotted grouper "Epinephelus coioides". All samples having the name of jesh were found to belong to the trevallys (Family Carangidae) that is more abundant in the Arabian Gulf than in the Gulf of Oman. Jesh TT samples were $100 \%$ identical to the orange-spotted trevally "Carangoides bajad". Most of the samples labeled as "jesh sal" showed $100 \%$ sequence identity with malabar trevally "C. malabaricus". However, a single sample labeled as "jesh sal" exhibited $100 \%$ sequence identity with a closely related species longnose trevally "C. chrysophrys". Jesh farow and shaari arabi samples exhibited $99-100 \%$ sequence identity with the blacktip trevally "Caranx heberi" and the spangled emperor "Lethrinus nebulosus", respectively. Similarly, the marjaan/al-hamra was $99-100 \%$ identical to the Pinjalo Pinjalo, while shaari eshkheli/baskili was $98.5 \%$ identical to the pinkear emperor "L. lentjan". In addition, the naiser and dog fish/baby shark exhibited $98-100 \%$ sequence identity with
L. ehrenbergii and the milk shark "Rhizoprionodon acutus", respectively.

For the phylogenetic analysis, the best substitution model for ML tree construction was $\mathrm{HKY}+\mathrm{G}$ substitution model with 1000 bootstrap. Five families were clearly identified in two major clades. Specifically, Epinephelidae, Carangidae, Lethrinidae and Lutjanidae represented the Osteichthyes, while Carcharhinidae represented the Chondrichthyes. All our samples grouped perfectly with the GenBank and BOLD references (Figure 3). Most species tested in the current study exhibited moderate to high haplotype diversity (Table 1). Those haplotypes were compared with the available references on GenBank and BOLD for counterparts from the directly related environments, i.e. the Arabian Gulf, the Sea of Oman, and the Red Sea. References for these environments in both databases from species identified in the current study were scarce, especially from the Sea of Oman. C. bajad and C. chrysophrys exhibited only one haplotype in common with the Arabian Gulf, while $C$. heberi had no references in the Arabian Gulf. C. malabaricus exhibited two haplotypes in common with the Arabian Gulf. All the three identified Carangoides species did not have any haplotype in common with the Arabian Gulf or the Sea of Oman. L. nebulosus exhibited two haplotypes in common with the Arabian Gulf and had no common with the Red Sea. L. ehrenbergii exhibited three haplotypes that were common with the Arabian Gulf, but not with the Red Sea. E. coioides exhibited one haplotype common with Arabian Gulf, but no references with Red Sea. Finally, $R$. acutus had no reference in the Red Sea but exhibited two haplotypes in common with Arabian Gulf (Figure 3).

\section{Reviewing species distribution}

All fish labels did not stated taxonomic and/or geographic information. Only the common names were declared in the labels. Reviewing the maps of species distribution available in FishBase (www.fishbase.org) and the related literature, the identified 


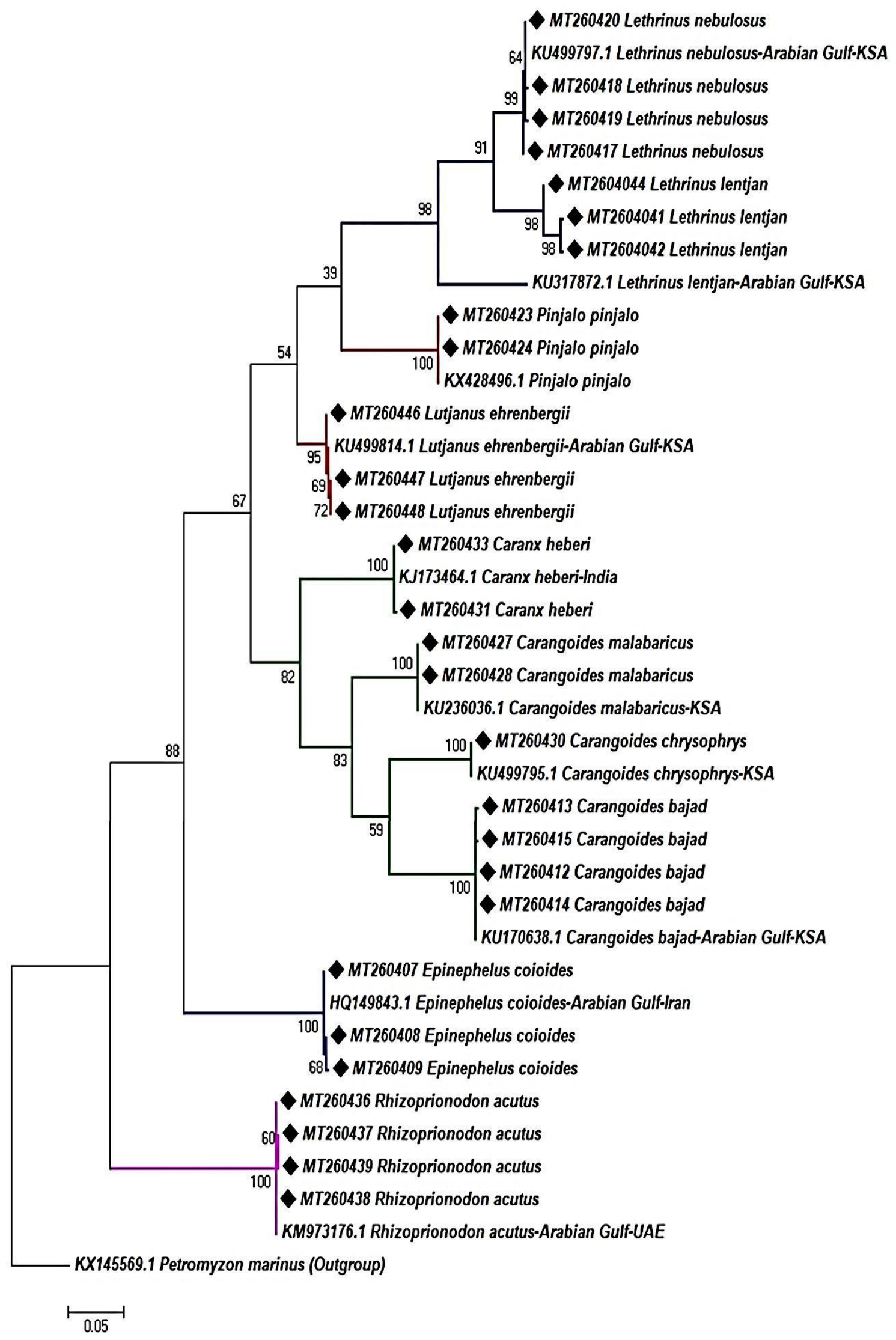

Figure 3: Molecular phylogenetic tree using maximum-likelihood tree method based on partial coi gene sequences including coi GenBank and BOLD reference sequences. Numbers at nodes are bootstrap values on 1000 replicates. 
species were found to be mainly present occupy the Sea of Oman and the Arabian Gulf. E. coioides and C. bajad are more abundantly present in the Arabian Gulf than in the Sea of Oman. L. nebulosus shows very little presence in the Sea of Oman, while being very abundant in the Arabian Gulf. Generally, the fish species detected in this study are more abundant in the Arabian Gulf than in the Sea of Oman, such as $P$. pinjalo, $R$. acutus, C. chrysophrys, C. malabaricus, Caranx heberi, L. lentjan, and L. ehrenbergii. Extending the comparison to the Red Sea, which locate in the same geographical region, we observed that all samples in our study are native to the Red Sea and almost equally distributed among the Red Sea countries.

\section{DISCUSSION}

Application of genetic markers for authentication of seafood market products is a subject of a growing interest in the Arabian Gulf and the Sea of Oman. This area is known since very early in history with extensive interest in fisheries and fisheries products. Being a central area for international trade, especially through maritime means, the UAE can be a plausible target for seafood market adulterations. For the best of authors' knowledge, the current study represents one of very few works that dealt with this subject in the UAE. The morphological similarities in some fresh fishes, and the absence of morphological characteristics from frozen products, make it crucial to provide adequate molecular clues for species identification. In the current study, nine fish species from seven genera and five families that are gaining the key interest for consumers in UAE fish markets could be unambiguously identified using coi gene sequencing. Despite the reports from fishermen that some of these fishes were actually caught days before being landed, the obtained PCR products and their sequences were good enough to provide clear species identification.

A key finding in the current study regarding the fish market is providing a basis for standardizing species nomenclature. This step is a key objective for fisheries management, as in many countries there is a lack of provisions for the labeling of fishery products and a standardized seafood nomenclature. Based on the nomenclature of fishes by the local sellers and the Fisheries Statistics Report for Abu Dhabi Emirate of the Environmental Agency $(\mathrm{EAD})^{[14]}$, some suggestions based on this study for species nomenclature can be added. Also, enforcing the use of the official names found in the EAD guide ${ }^{[14]}$ on the local fish market should be carried out. In this context, our results indicated the presence of some contrast in the fish nomenclature between the EDA and local sellers. Concisely, local sellers use the name jesh TT for Carangoides bajad, despite being the name for this species mentioned in the EAD report is jesh um al hala ${ }^{[14]}$. C. chrysophrys is not included in the report, yet it is named in the market as jesh sal. Despite the EAD report used the generic name shaari for Lethrinus nebulosus ${ }^{[14]}$; it is sold in the market as shaari arabi. Pinjalo pinjalo, named in the EAD report as neimi ${ }^{[14]}$, was found to be marketed under two names: al-hamra and marjaan, whose report species designations are Lutjanus malabaricus and L. argentimaculatus. Rhizoprionodon acutus is specifically named as korsh khartoum al maqran labani in the report. However, it is named by a very generic name in the market, which is the "dog fish" or "baby shark". The reasons of such misnaming may be primarily the morphological similarities. Lutjanus malabaricus is known to share similar morphological characteristics with $P$. pinjalo $^{[15]}$. Likewise, Ehrenberg's snapper "Lutjanus ehrenbergii" and blackspot snapper " $L$. fulviflamma" are very morphologically similar ${ }^{[15]}$. L. ehrenbergii is named in the report as blackspot snapper.

In a country whose economy has a key income from fish products trades like the UAE, efforts for market control, and assuring of market products traceability are always encouraged. In this study, the labels 
for all assessed species were lacking such detailed labeling. This may trigger the possible presence of overexploited, endangered, and price-adulterated species in food products. In this context, some ecological concerns were revealed in relation to some species identified in the current study. For instance, the local sellers use the name "hamour" for Epinephelus coioides. According to EAD report, E. coioides is being fished on average 3.5 times the sustainable limit, and this resource is considered severely overexploited ${ }^{[14]}$. Indeed, the International Union for Conservation of Nature (IUCN) red list was listed $E$. coioides or "hamour" in the Arabian Gulf as vulnerable status. Hamour is considered one of the principal fish species in the UAE. Shaari eshkheli, shaari, and jesh um al hala are also listed as over-exploited. The UAE Sustainable Fisheries Program is aiming to move them from the current "severely overexploited" state of the fishery towards a "recovering" state finally by 2030 . Hence, and in order to provide better market traceability, besides assuring proper species conservation, more accurate species labeling must be included in the fish markets of the UAE. Mislabeling and species misnaming may hinder fisheries conservation strategies due to trade in overfished or threatened species under different names of species that do not confront similar threats ${ }^{[16]}$. For examples, $56 \%$ of the species sold as Pacific red snapper in California (CA, USA) were actually overfished rockfish species Sebastes $\operatorname{spp}^{[17]}$. In South Africa, mislabeling occurred for 27 of 149 studied species. For example, the Spanish/king mackerel was sold as barracuda (Sphyraena spp.), and the red drum "Sciaenops ocellatus" was labeled as a generic name, i.e. sea bass. Another example is the severely overexploited red stumpnose "Chrysoblephus gibbiceps" that was sold as the white stumpnose "Rhabdosargus globiceps",[18]. In addition, in Canada, the Japanese amberjack "Seriola quinqueradiata" was sold as the yellowfin tuna "Thunnus albacares", which is categorized as near-threatened species in the IUCN red list of species ${ }^{[19]}$. Moreover, the overfished red snapper "Lutjanus campechanus" is usually misnamed or substituted with another low price and less vulnerable species, such as rockfish and sea bream ${ }^{[20]}$.

In conclusions, application of DNA barcoding appeared to be crucial for assuring authenticity and traceability in the Emirati seafood markets. The controversies in the nomenclature of some species among the fishermen may produce a stress on the native fisheries. This problem that can also be avoided through continuous screening of seafood markets especially by molecularbased methodologies. Finally, the tools and results of the current study can support the continuous efforts of the UAE food authorities to induce authenticity and sustainability in seafood markets.

\section{FUNDING SOURCE DISCLOSURE}

This study received no specific grant from any funding agency in public, commercial, or not-for-profit sectors.

\section{CONFLICT OF INTEREST}

The authors declare no conflict of interest.

\section{REFERENCES}

[1] Ortea, I.; Pascoal, A.; Cañas, B. et al. (2012). Food authentication of commercially-relevant shrimp and prawn species: from classical methods to foodomics. Electrophoresis, 33(15): 2201-2211.

[2] FAO (2019). A Quarterly Update on World Seafood Markets. Food and Agriculture Organization of the United Nations, Rome, Italy (http://www.fao. org/3/ca4185en/ca4185en.pdf).

[3] FAO (2016). Fishery and Aquaculture Country Profiles, the United Arab Emirates. Food and Agriculture Organization of the United Nations, Rome, Italy (http://www.fao.org/ fishery/facp/ARE/en)

[4] The UAE National Framework Statement for Sustainable Fisheries (2019-2030). Environment Agency- 
Abu Dhabi in partnership with the Ministry of Climate Change \& Environment (https://www.ead.gov.ae/ storage/Post/files/8207d3c3daec608b1 2636ef7ab 2793ff.pdf).

[5] Galal-Khallaf, A.; Ardura, A.; Borrell, Y. J. et al. (2016). PCR-based assessment of shellfish traceability and sustainability in international Mediterranean seafood markets. Food chemistry, 202: 302-308.

[6] Galal-Khallaf, A.; Ardura, A.; Mohammed-Geba, K. et al. (2014). DNA barcoding reveals a high level of mislabeling in Egyptian fish fillets. Food Control, 46: 441-445.

[7] Xiong, X.; Yuan, F.; Huang, M. et al. (2019). DNA barcoding revealed mislabeling and potential health concerns with roasted fish products sold across China. J Food Prot, 82(7): 1200-1209.

[8] Galal-Khallaf, A.; Osman, A. G. M.; El-Ganainy, A. et al. (2019). Mitochondrial genetic markers for authentication of major Red Sea grouper species (Perciformes: Serranidae) in Egypt: a tool for enhancing fisheries management and species conservation. Gene, 689: 235245.

[9] Chen, K.-C.; Zakaria, D.; Altarawneh, H. et al. (2019). DNA barcoding of fish species reveals low rate of package mislabeling in Qatar. Genome, 62(2): 69-76.

[10] Mohammed-Geba, K.; Hassab ElNabi, S. E. and El-Desoky, M. S. (2016). Development of cytochrome-coxidase 1 specific primers for genetic discrimination of the European eel Anguilla anguilla (Linnaeus, 1758). Journal of Bioscience and Applied Research, 2(4): 258-262.

[11] Ward, R. D.; Zemlak, T. S.; Innes, B. H. et al. (2005). DNA barcoding Australia's fish species. Philosophical Transactions of the Royal Society B: Biological Sciences, 360(1462): 1847-1857.
[12] Kumar, S.; Stecher, G.; Li, M. et al. (2018). MEGA X: molecular evolutionary genetics analysis across computing platforms. Mol Biol Evol, 35(6): 1547-1549.

[13] Librado, P. and Rozas, J. (2009). DnaSP v5: a software for comprehensive analysis of DNA polymorphism data. Bioinformatics, 25(11): 1451-1452.

[14] Annual Fisheries Statistics Report for Abu Dhabi Emirate 2018, Project 5114020-511501. Environment Agency-Abu Dhabi (https://www.ead. gov.ae/storage/Post/files/c757e725bdc ed1e1bd4e16039ab0bc8c.pdf).

[15] Chu, C.; Rizman-Idid, M. and Ching, C. V. (2013). Phylogenetic relationships of selected genera of Lutjanidae inferred from mitochondrial regions, with a note on the taxonomic status of Pinjalo pinjalo. Ciencias Marinas, 39(4): 349361.

[16] Giovos, I.; Arculeo, M.; Doumpas, N. et al. (2020). Assessing multiple sources of data to detect illegal fishing, trade and mislabelling of elasmobranchs in Greek markets. Marine Policy, 112: 103730 (DOI: 10.1016/ j.marpol.2019.103730).

[17] Logan, C. A.; Alter, S. E.; Haupt, A. J. et al. (2008). An impediment to consumer choice: overfished species are sold as Pacific red snapper. Biological Conservation, 141(6): 1591-1599.

[18] Cawthorn, D. M.; Steinman, H. A. and Witthuhn, R. C. (2011). Evaluating the availability of fish species on the South African market and the factors undermining sustainability and consumer choice. Food Control, 22(11): 1748-1759.

[19] Hanner, R.; Becker, S.; Ivanova, N. V. et al. (2011). FISH-BOL and seafood identification: geographically dispersed case studies reveal systemic market substitution across Canada. Mitochondrial DNA, 22: 106-122. 
[20] Isaacs, R. B. and Hellberg, R. S. DNA barcoding. Food Control, 118: (2020). Authentication of red snapper (Lutjanus campechanus) fillets using 107375 (DOI: 10.1016/j.foodcont. a combination of real-time PCR and 2020.107375).

\section{How to cite this article:}

Abdelbaset-Donya, A.; Hamza, W.; Mohammed-Geba, K.; Galal-Khallaf, A. (2020). Application of DNA barcoding for identification of some key fish-market species in Sharjah city, UAE. Egyptian Journal of Zoology, 74: 56-66 (DOI: 10.12816/ejz.2020.47282.1042). 


\section{تطبيق التثفير اللوحي للحمض النووي "دنا" لتحديد بعض أنواع الأسماك الرئيسية

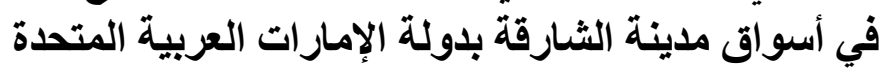

\section{آلاء عبدالباسط دنيا1، وليد حمزةّ، خالد محمد جبة'، أسماء جلال خلاف1}

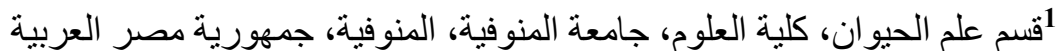

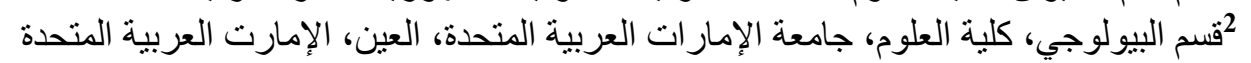

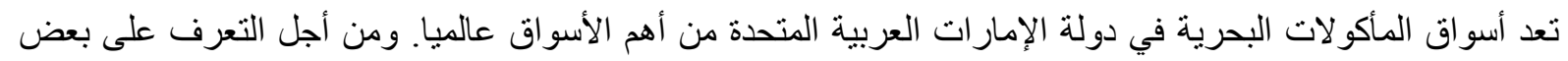

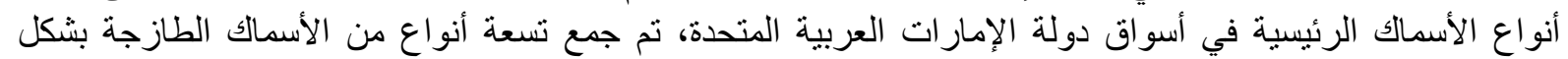

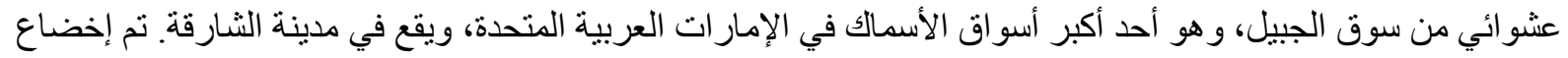

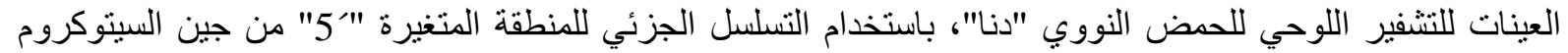

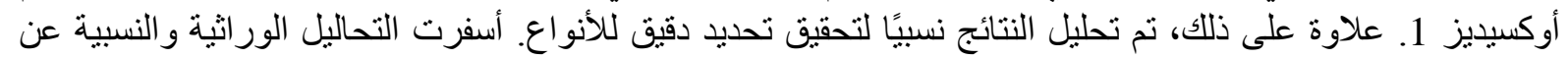

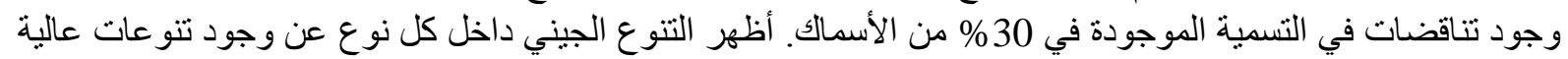

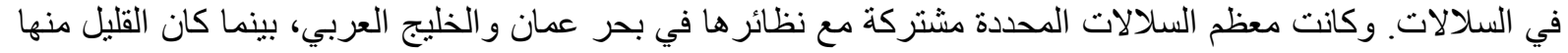

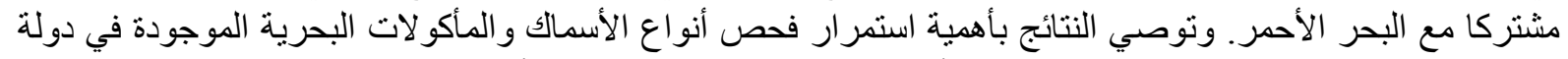

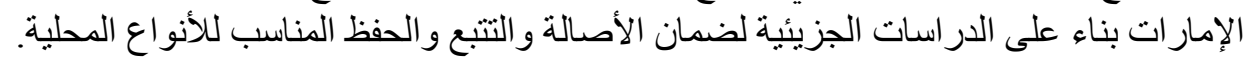

